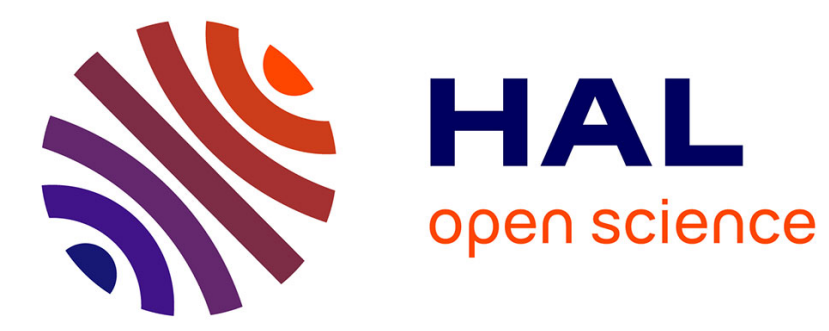

\title{
Design and experimentation of an LPV extended state feedback control on Electric Power Steering systems
}

Kazusa Yamamoto, Olivier Sename, Damien Koenig, Pascal Moulaire

\section{To cite this version:}

Kazusa Yamamoto, Olivier Sename, Damien Koenig, Pascal Moulaire. Design and experimentation of an LPV extended state feedback control on Electric Power Steering systems. Control Engineering Practice, 2019, 90, pp.123-132. 10.1016/j.conengprac.2019.06.004 . hal-02169682

\section{HAL Id: hal-02169682 \\ https://hal.univ-grenoble-alpes.fr/hal-02169682}

Submitted on 25 Oct 2021

HAL is a multi-disciplinary open access archive for the deposit and dissemination of scientific research documents, whether they are published or not. The documents may come from teaching and research institutions in France or abroad, or from public or private research centers.
L'archive ouverte pluridisciplinaire HAL, est destinée au dépôt et à la diffusion de documents scientifiques de niveau recherche, publiés ou non, émanant des établissements d'enseignement et de recherche français ou étrangers, des laboratoires publics ou privés.

\section{(ㄷ)(1) $\$$}

Distributed under a Creative Commons Attribution - NonCommerciall 4.0 International 


\title{
Design and Experimentation of an LPV Extended State Feedback Control on Electric Power Steering Systems
}

\author{
Kazusa Yamamoto ${ }^{\mathrm{a}, \mathrm{b}, *}$, Olivier Sename ${ }^{\mathrm{a}}$, Damien Koenig ${ }^{\mathrm{a}}$, Pascal Moulaire ${ }^{\mathrm{b}}$ \\ ${ }^{a}$ Univ. Grenoble-Alpes, CNRS, Grenoble INP, GIPSA-lab, 38000 Grenoble, France \\ ${ }^{b}$ JTEKT Europe, ZI du Broteau, 69540 Irigny, France
}

\begin{abstract}
This paper deals with Column-type Electric Power Steering systems. An $\mathcal{H}_{\infty}$ state-feedback Linear Parameter-Varying controller is developed considering a parameter-dependent Lyapunov function. For practical implementation, an $\mathcal{H}_{\infty} / \mathcal{H}_{2}$ Proportional Integral observer is added for state and driver torque estimation. The whole observer-based control has been implemented in real-time using dSpace/MicroAutobox on a test car. Some driving tests have been carried out on a test track, and promising results are achieved regarding both estimation and control performances.
\end{abstract}

Keywords: Automotive Systems, Electric Power Steering systems, Linear Parameter Varying state-feedback, Proportional Integral Observer Design

\section{Introduction}

Nowadays, modern vehicles are equipped with more and more automotive embedded systems as the famous Electronic Stability Program and Anti-lock Braking System. Looking at the current trend concerning autonomous vehicles, Advanced Driving Assistance Systems (ADAS) as e.g. Lane Keeping Assistance, are common equipment now. It is worth noting that the Electric Power Steering (EPS) system is a key component of ADAS as shown in Matsuoka (2016). The steering system creates an interaction between the driver and the vehicle wheels in order to turn in the desired direction. To overcome manual steering issues (heavy or low-geared steering), Power-Assisted Steering systems have been developed. Moreover, EPS systems have significant advantages such as: fuel economy, tunability of the steering feel and ease of integration with other subsystems. Therefore, the EPS system is a relatively new trend to equip recent cars in place of traditional Hydraulic Power Steering (HPS) ones (see Noguchi (2001); Qun and Juhua (2009)).

Thanks to an electrical assistance motor, EPS provides an additional torque to reduce the amount of effort

\footnotetext{
${ }^{*}$ Corresponding author

Email addresses: kazusa. yamamoto@grenoble-inp.fr (K. Yamamoto), olivier.sename@grenoble-inp.fr (O. Sename), damien.koenig@grenoble-inp.fr (D. Koenig), pascal.moulaire@jtekt.eu (P. Moulaire)
}

produced by the driver to turn the wheels. Today the amount of supplied power is computed in the Electronic Control Unit (ECU) by a torque control law including an assistance rule depending mainly on a torque sensor signal and on the vehicle speed. Indeed, the torque sensor measures the applied steering torque at the torsion bar level which is used to define the required assistance (typically, through static base assist curves and other functions e.g. returnability, inertia compensation, etc) as explained in Kozaki et al. (1999), Badawy et al. (1999). Thus, a torque sensor failure commonly leads to a sudden loss of assistance deteriorating driving safety and comfort. According to new automotive safety rules ISO26262, such a situation is expected to be avoided. The proposed solution, considered in this study, and which is still an open problem, is to develop a controller free of the torque sensor. This problem is tackled here in the Linear Parameter Varying (LPV) framework.

\subsection{Related works}

Most of the studies concerning the control of EPS systems do consider the use of the torque sensor signal (at the torsion bar). Let us mention a few such as linear PI control design in Kim and Song (2002), LQR in Parmar and Hung (2004), admittance control in Yang (2015), or the fuzzy non linear control in Saifia et al. (2014). When this sensor is in failure, fault tolerant control strategies have been proposed in Cholakkal and Chen (2009); Lawson and Chen (2008) by switching to 
an estimation based controller when a fault residual exceeds a defined threshold.

Now, since the driver torque is a key variable in such EPS systems (in particular to control the steering feel), better performance and stability margins have been obtained in Chabaan and Wang (2001) where the EPS control was designed using the driver torque instead of the measured torsion bar torque. Indeed some driver torque estimation methods have been developed either using the torque sensor signal Illán et al. (2011), or using vehicle measurements only Marouf et al. (2010).

Note that the EPS control design based on a driver torque estimation has not been much discussed up to now. An interesting approach is presented in Marouf et al. $(2011,2012)$ where sliding mode control and observer synthesis have been proposed.

On the other hand, the LPV approach is known to be powerful to handle system non linearities by considering them as varying parameters and/or to design gainscheduled controllers (see Sename et al. (2013)). However, few studies use such an LPV approach for EPS systems. In Rongyun et al. (2015) an LPV/ $\mathcal{H}_{\infty}$ control has been developed to ensure performances and good driver's steering feel. The considered varying parameters of the LPV model are the column stiffness, the motor magnetic reluctance and the worm/gear reduction ratio, hardly measured or estimated in practice. In Yamamoto and Nishimura (2011) a gain-scheduled control has been designed to obtain an HPS like steering feel, considering two varying parameters: the torque sensor and the vehicle speed. This seems a natural choice of the scheduling parameters, suitable to meet the EPS requirements.

In this paper an LPV approach is proposed that accounts, in an original parameter-dependent formulation, for an existing boost gain (base assist) in the control structure, which is a function of the driver torque. Compared to previous studies, the proposed design considers the steering performance through the modelling of LPV EPS model and concerns the design of an extended LPV state-feedback, whereas in Yamamoto and Nishimura (2011) the scheduling parameters for the dynamic output feedback controller only appear in the weighting functions.

\subsection{Paper contribution}

For the first time, a sensor-less observer-based LPV state feedback is developed for a C-EPS system (Column type EPS using an assist motor located on the column, close to the driver), is validated with experiments, and ensures industrial cost reduction. lows:

The paper contributions can be summarized as fol-

- A new LPV state feedback control formulation is proposed in the field of EPS systems. The design method is done in the $H_{\infty}$ framework considering a parameter dependent Lyapunov function that allows to reduce the conservatism.

- The model-based control strategy ensures stability and performances. It can be easily reproduced by control engineers, so leading to less development costs than an empirical approach that may be difficult and long to be tuned. Indeed, the latter intrinsically needs an ad-hoc fine tuning using on-board experimental tests, which may seem less reliable for knowledge sharing than a model-based strategy.

- The real-time implementation uses a PI observer that estimates the driver torque with only the steering wheel angle and motor angle sensors (that are common on-board sensors).

- The approach is validated in real industrial experimental conditions.

- Finally it is worth noting that this approach allows to reduce the EPS production costs since it does not need any torque sensor unlike today's industrial systems that do need this costly sensor.

The paper is organized as follows. Section 2 presents the vehicle experimental set-up. Section 3 gives the considered EPS system model based on mechanical equations. Section 4 describes the control design problem introducing an LPV EPS system model, and section 5 is dedicated to a grid-based parameter dependent LPV state-feedback control strategy. Section 6 discusses the practical implementation including the PI observer design. Experimental results are shown in Section 7. Finally, section 8 draws some concluding remarks.

\section{Vehicle set-up}

Fig. 1 presents the whole experimental vehicle environment. The test car considered in this framework, is a Clio IV equipped with a prototype C-EPS system using modified mechanical parameters (i.e. pinion/rack reducer). The on board sensors are the resolver (motor angle sensor) and the steering wheel angle sensor (these sensors are used for observer). Also, several specific elements such as a dynamometer steering wheel (for driver torque) and instrumented tie-rods (for rack force), 


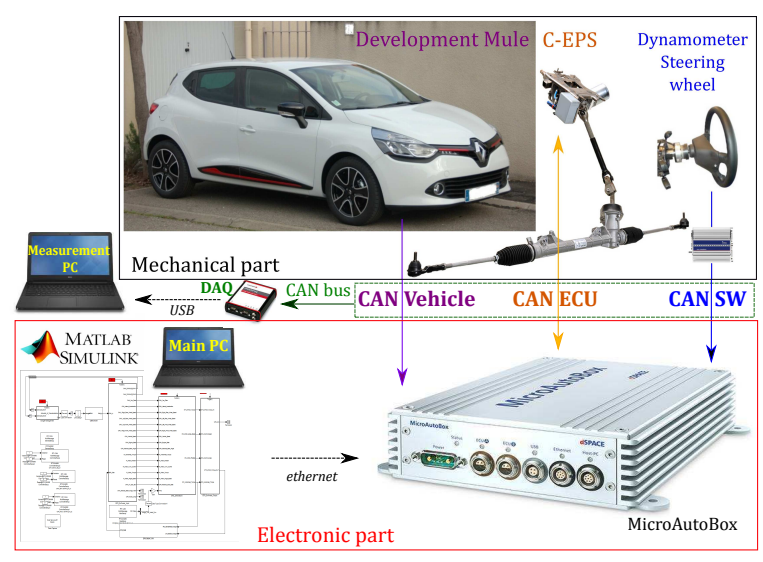

Figure 1: Vehicle environment, Experimental set-up

have been added on the vehicle for data acquisition and validation purposes. It is worth noting that, due to the experimental set-up, measurement noise appears on the acquired signal (in this case represented by spike). Considering the real time part, a dSpace rapid prototyping system has been used. Indeed, the strategy designed under Matlab/Simulink is directly implemented on the MicroAutoBox II hardware.

\section{EPS System and Modelling}

In this part, the considered C-EPS system model is defined. An illustration of the C-EPS systems, similarly as in El-Shaer et al. (2009); Mehrabi et al. (2011), is shown in Fig. 2, where three main parts are involved: steering wheel, assist motor and rack.

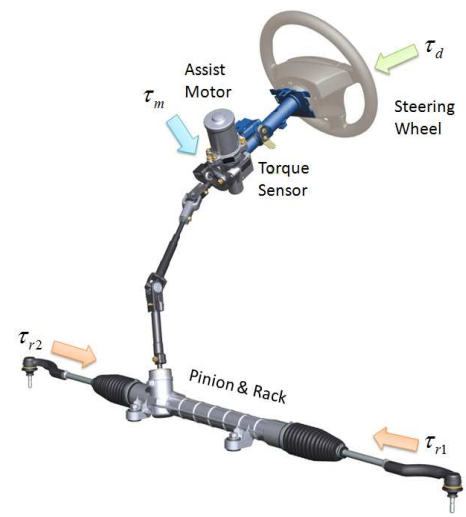

Figure 2: C-EPS Dynamic Modelling

The following equations are obtained from Newton's second law, neglecting dry frictions,
- at the steering wheel:

$$
J_{c} \ddot{\theta}_{c}=\tau_{d}-D_{c}\left(\dot{\theta}_{c}-\frac{\dot{\theta}_{m}}{R_{m}}\right)-K_{c}\left(\theta_{c}-\frac{\theta_{m}}{R_{m}}\right)-B_{c} \dot{\theta}_{c}
$$

where the torque sensor signal (torsion bar torque) is considered as:

$$
\tau_{t s}=K_{c}\left(\theta_{c}-\frac{\theta_{m}}{R_{m}}\right)+D_{c}\left(\dot{\theta}_{c}-\frac{\dot{\theta}_{m}}{R_{m}}\right)
$$

at the assist motor shaft:

$$
\begin{aligned}
J_{e q} \ddot{\theta}_{m} & =\tau_{m}+\frac{D_{c}}{R_{m}}\left(\dot{\theta}_{c}-\frac{\dot{\theta}_{m}}{R_{m}}\right)+\frac{K_{c}}{R_{m}}\left(\theta_{c}-\frac{\theta_{m}}{R_{m}}\right) \\
& -B_{m} \dot{\theta}_{m}-K_{r} \frac{R_{p}^{2}}{R_{m}^{2}} \theta_{m}-D_{r} \frac{R_{p}^{2}}{R_{m}^{2}} \dot{\theta}_{m}-\frac{\tau_{r}}{R_{m}}
\end{aligned}
$$

where the equivalent inertia and viscous friction are expressed as:

$$
\begin{gathered}
J_{e q}=J_{m}+\frac{R_{p}^{2}}{R_{m}^{2}} M_{r} \\
B_{e q}=B_{m}+\frac{R_{p}^{2}}{R_{m}^{2}} D_{r}
\end{gathered}
$$

and with the position conversion from rack to pinion and from motor to pinion as:

$$
\begin{aligned}
& X_{r}=R_{p} \theta_{p} \\
& \theta_{m}=\theta_{p} R_{m}
\end{aligned}
$$

The mechanical parameters are described in Table 1.

\begin{tabular}{ll} 
Notation & Description \\
\hline$J_{c}$ & Steering column inertia \\
$B_{c}$ & Steering column viscous friction \\
$K_{c}$ & Column stiffness \\
$D_{c}$ & Column damping \\
$F_{c}$ & Steering column friction \\
$R_{p}$ & Pinion/rack reducer \\
$M_{r}$ & Rack and tie rods mass \\
$B_{r}$ & Rack viscous friction \\
$K_{r}$ & Rack stiffness \\
$D_{r}$ & Rack damping \\
$R_{m}$ & Motor reduction ratio \\
$J_{m}$ & Motor inertia \\
$B_{m}$ & Motor viscous friction \\
$F_{m}$ & Motor friction \\
\hline
\end{tabular}

Table 1: C-EPS system mechanical parameters 


\begin{tabular}{lll} 
Notation & Variables & Description \\
\hline \multirow{4}{*}{$x$} & $\dot{\theta}_{c}$ & Steering wheel speed \\
& $\theta_{c}$ & Steering wheel angle \\
& $\dot{\theta}_{m}$ & Assist motor speed \\
$u$ & $\theta_{m}$ & Assist motor angle \\
$d$ & $\tau_{m}$ & Assist Motor Torque \\
$w$ & $\tau_{d}$ & Driver Torque \\
& $\tau_{r}$ & Road Reaction Torque \\
$y$ & $\theta_{c}$ & Steering wheel angle \\
& $\theta_{m}$ & Assist motor angle \\
\hline
\end{tabular}

Table 2: State-space representation variables

From the previous mechanical equations, a statespace representation (whose matrices are defined in Appendix A) is expressed as:

$$
\left\{\begin{array}{l}
\dot{x}=A x+B u+E d+W w \\
y=C x
\end{array}\right.
$$

where the variables are defined in Table 2.

It could be emphasized that the rack force increases as the vehicle speed increases, as shown in Fig. 3 where the curves (rack force vs steering wheel angle) are plotted at $15 \mathrm{~km} / \mathrm{h}$ and $30 \mathrm{~km} / \mathrm{h}$. The steering effort depends on the road reaction torque to be overcome (which is deduced from the rack force), but the steering feel is expected to be sensitive to a loss of adherence. Thereby the road reaction torque is not considered in the control design problem, yet in the observer design it is.

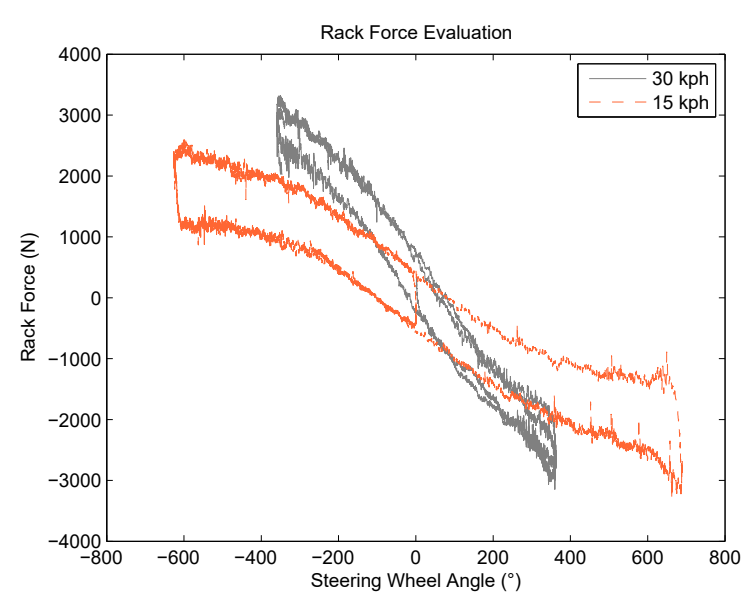

Figure 3: Rack forces measured at $15 \mathrm{~km} / \mathrm{h}$ and $30 \mathrm{~km} / \mathrm{h}$

\section{Control design problem}

Since it is related to the human feeling, the EPS performance is not straightforward to be defined when it comes to quantification El-Shaer (2008). Key points to be handled in the design are the driver feeling and the robustness.

The main requirement, is to provide a suitable assistance torque, which is commonly achieved through a characteristic curve that ensures an appropriate reduction of the driver effort and shapes the assist level Zhang et al. (2009).

Indeed, the steering effort could be tuned using a boost gain (motor assist torque) through a practical approach. Therefore, the base assist depends on the driver torque $d$ and is represented as a simple controller $K(\hat{d})$ (since it needs a real-time implementation of the driver torque estimation).
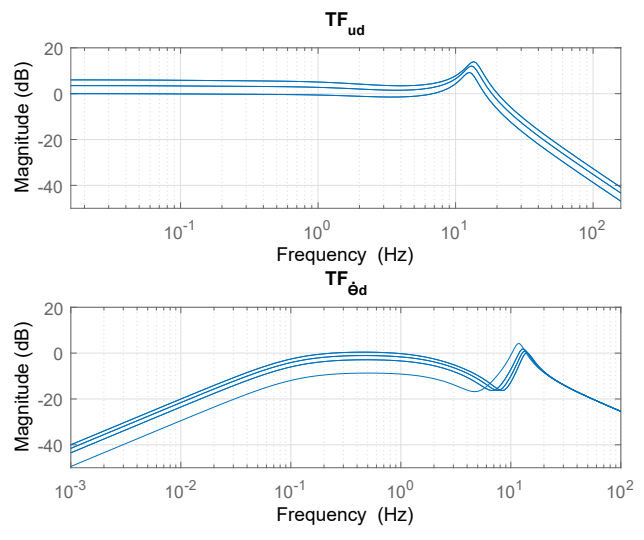

Figure 4: EPS performance using simple controller

EPS performance could be evaluated subject to the influence of the driver torque $d$ over the steering wheel speed $\dot{\theta}_{c}$ and also the assist motor torque $u$. As shown in Fig. 4 where frozen Bode plots of the (closed-loop) system transfer functions $\frac{u}{d}$ and $\frac{\dot{\theta}}{d}$ are given for several chosen values of the gain $K(\hat{d})$, this characteristic curve cannot ensure the performances of the closedloop system, under model uncertainties (e.g. parameter, unknown inputs) and non-linearities (e.g. friction). Therefore, the proposed approach is to develop an LPV state-feedback controller considering an LPV EPS system model incorporating the boost gain $K(\rho=\hat{d})$.

Now, the performance requirements include the driving comfort and feeling, which are considered thanks to the LPV EPS model including $K(\hat{d})$. Regarding safety, closed-loop stability is compulsory to avoid steering wheel oscillations. Moreover the assist motor torque limitation must be taken into account. Such performances will be handled in the $H_{\infty}$ framework through weighting functions, and an extended state-feedback controller will be designed for the LPV system model. 
More details are provided in the next section.

On the other hand, an observer has to be developed (this is done in section 6), since the driver input is not measured on the real test car. The practical scheme of the observer-based control structure is shown in Fig 5. The LPV extended state feedback controller $F(\rho=\hat{d})$ will be designed from a C-EPS system model incorporating the characteristic curve $K(\hat{d})$. Furthermore, since the driver torque $d$ and the state variables are not measured, a PI observer is proposed for estimation purpose.

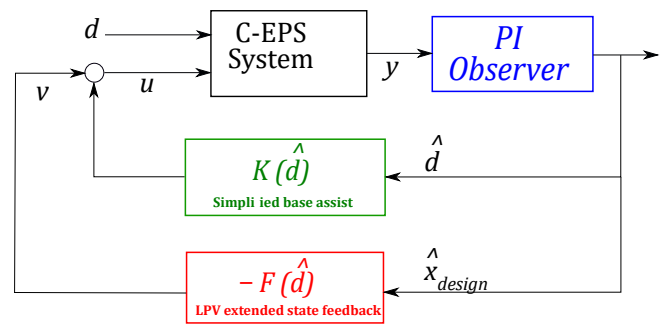

Figure 5: Observer-based control structure

According to the above mentioned problem, the considered LPV EPS system model is as follows :

$$
\dot{x}=A(\rho) x+B v+E d
$$

where $x \in \mathbb{R}^{4}$ is the EPS system state vector, $d \in \mathbb{R}$ is the driver torque, $v \in \mathbb{R}$ is the (state-feedback) control input. $A(\rho)$ incorporates the boost gain $K(\rho)$ as $A(\rho)=$ $A+B K(\rho) \tau_{t s}$, where $\rho=\hat{d}$ (the estimated driver torque). Details are given in Appendix B.

Remark 1. Considering implementation, the strategy is such that the LPV state-feedback controller is based on the driver torque estimation, i.e. $\rho=\hat{d}$ since the torque sensor is assumed to be not available. Moreover, since the driver torque acts directly on the steering feel and on the assistance level, this parameter choice is of high interest.

Remark 2. It should be noticed that considering the vehicle speed in the design step may improve the steering feel, since the road reaction force is sensitive to the vehicle speed Kozaki et al. (1999). Indeed, based on the previous explanations, the steering torque and vehicle speed are important to characterize EPS systems. Besides, the two signals values are limited and also ratebounded as the vehicle acceleration and the derivative of steering torque are limited. Therefore, both signals could be used to define the vector of parameters of the LPV EPS system model. Nevertheless, in order to reduce the implementation complexity, the scheduling parameter $\rho$ is defined here as the torsion bar torque $\tau_{t s}=C_{t s} x$ only. In practice, $\rho$ is computed as the estimated variable $\hat{d}$ coming from the observer detailed in Section 6.

The following generalized assumptions are made on the vector of varying parameters:

- $\rho$ is measurable or at least estimated, and $\rho \in X_{\rho}$ with $X_{\rho}=\left\{\rho=\left[\rho_{1}, \rho_{2}, \ldots, \rho_{s}\right] \in \mathbb{R}^{s}, \rho_{k} \leq \rho_{k} \leq \overline{\rho_{k}}\right\}$ a compact set and $k=1 \ldots s$ with $s$ the number of varying parameters

- $\dot{\rho}$ the derivative of $\rho$, is bounded i.e. $\left|\dot{\rho}_{k}\right|<v_{k}$ with $k=1 \ldots s$ and $v=\left[v_{1}, v_{2}, \ldots, v_{s}\right] \in \mathbb{R}^{s}$

\section{LPV State feedback Controller}

In this section, the design of LPV state-feedback controller, based on the previous LPV EPS model, is detailed.

\subsection{LPV state feedback problem formulation}

As explained in section 4, the design objective is to find a controller ensuring a suitable steering performance (low ripple, reduced driver's effort) subject to actuator constraints. To solve this problem, we have chosen an $H_{\infty}$ control framework including two weighting functions in order to handle:

- the actuator constraints through the weighting function $W_{v}(s)=\frac{z_{v}}{v}$.

A low pass filter appears to be a suitable choice, since the assist torque is provided only at low frequency (the driver torque acting range reaches hardly 3 to $5 \mathrm{~Hz}$ Badawy et al. (1999)). It is given by the state space representation:

$$
W_{v}(\cdot)\left\{\begin{aligned}
\dot{x}_{v} & =A_{v} x_{v}+B_{v} v \\
z_{v} & =C_{v} x_{v}+D_{v} v
\end{aligned}\right.
$$

- the required performances according to the steering wheel velocity with the weighting function $W_{p}(s)=\frac{z_{p}}{\dot{\theta}_{c}}$.

In a first approach we could consider an ideal EPS behaviour of the form $J_{c} \ddot{\theta}=\tau_{d}$ as proposed in Coudon (2007). However, from a practical point of view, a stable transfer function is preferred for $W_{p}(s)$. Hence adding $\dot{\theta}$ in the previous ideal equation such that $J_{c} \ddot{\theta}+B_{c} \dot{\theta}=\tau_{d}$. Indeed, through the weighting function $W_{p}(s)$, it means that a slight 
driver torque enables to move the hand-wheel.

It is given by the state space representation:

$$
W_{p}(\cdot)\left\{\begin{aligned}
\dot{x}_{p} & =A_{p} x_{p}+B_{p} \dot{\theta}_{c} \\
z_{p} & =C_{p} x_{p}+D_{p} \dot{\theta}_{c}
\end{aligned}\right.
$$

These chosen weighting functions are represented in Fig. 9 and Fig. 10.

In Fig. 6, the extended plant including the weighting functions to achieve the design objectives is shown.

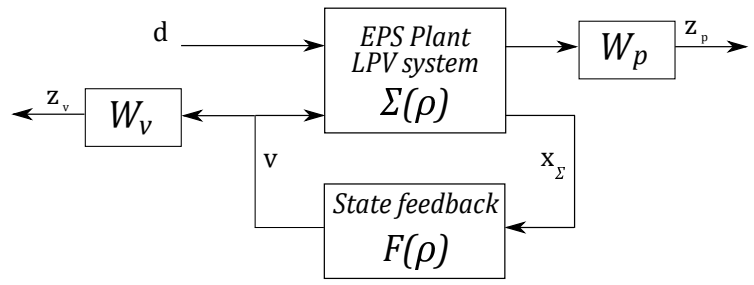

Figure 6: LPV State-feedback Controller Design

The augmented plant could be defined as:

$$
\left\{\begin{array}{l}
\left(\begin{array}{c}
\dot{x} \\
\dot{x}_{v} \\
\dot{x}_{p}
\end{array}\right)=\left(\begin{array}{ccc}
A(\rho) & 0 & 0 \\
0 & A_{v} & 0 \\
B_{p} C_{\dot{\theta}_{c}} & 0 & A_{p}
\end{array}\right)\left(\begin{array}{c}
x \\
x_{v} \\
x_{p}
\end{array}\right)+\left(\begin{array}{c}
B \\
B_{v} \\
0
\end{array}\right) v+\left(\begin{array}{c}
E \\
0 \\
0
\end{array}\right) d \\
\left(\begin{array}{c}
z_{v} \\
z_{p}
\end{array}\right)=\left(\begin{array}{ccc}
0 & C_{v} & 0 \\
D_{p} C_{\dot{\theta}_{c}} & 0 & C_{p}
\end{array}\right)\left(\begin{array}{c}
x \\
x_{v} \\
x_{p}
\end{array}\right)+\left(\begin{array}{c}
D_{v} \\
0
\end{array}\right) v
\end{array}\right.
$$

where $C_{\dot{\theta}_{c}}=\left[\begin{array}{llll}1 & 0 & 0 & 0\end{array}\right]$ and $x_{\Sigma}=\left(\begin{array}{lll}x^{T} & x_{v}^{T} & x_{p}^{T}\end{array}\right)^{T}$ is the full state.

The generalized plant expressed in the standard $H_{\infty}$ control framework is illustrated in Fig. 7:

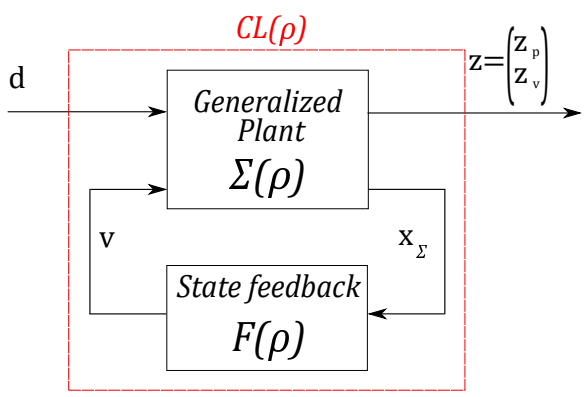

Figure 7: LPV State-feedback Controller Design

The parameter dependent LPV state-feedback is designed from the previous extended state space representation, in order to minimize the induced $\mathcal{L}_{2}$ norm from the external input $d$ to the controlled output vector $z=\left(\begin{array}{ll}z_{v} & z_{p}\end{array}\right)^{T}$, i.e. to ensure that $\left\|T_{z d}(s)\right\|_{\infty}<\gamma$ (where $\gamma$ is to be minimized).

\subsection{LPV state feedback design}

Let us consider the LPV state-space representation of the generalized plant:

$$
\begin{cases}\dot{x}_{\Sigma} & =\mathcal{A}_{\Sigma}(\rho) x_{\Sigma}+\mathcal{B}_{d}(\rho) d+\mathcal{B}_{v}(\rho) v \\ z & =\mathcal{C}_{z}(\rho) x_{\Sigma}+\mathcal{D}_{z d}(\rho) d+\mathcal{D}_{z v}(\rho) v\end{cases}
$$

with $x_{\Sigma}=\left(\begin{array}{lll}x^{T} & x_{v}^{T} & x_{p}^{T}\end{array}\right)^{T}$.

It is worth noting that, in this study, as given in (12) and in Appendix B2, only $\mathcal{A}_{\Sigma}(\rho)$ is parameter dependent (the other matrices are LTI).

Now, following $\mathrm{Wu}$ (1995), the next theorem ensures the existence of a parameter dependent LPV statefeedback controller $v=-F(\rho) x_{\Sigma}$ which guarantees that the closed loop system is stable and that the induced $L_{2}$ norm from $d$ to $z$ less than $\gamma>0$.

Theorem 1. Consider the LPV model (13) with parameters trajectories $\rho$ defined on the set $X_{\rho}$, and with bounded parameter variation rate $|\dot{\rho}| \leq v$.

If there exists parameter dependent matrices $P(\rho)=$ $P(\rho)^{T}>0$ and $Y(\rho)$ such that:

$$
\left(\begin{array}{ccc}
\mathcal{A}_{\Sigma}(\rho) P(\rho)+P(\rho) \mathcal{A}_{\Sigma}(\rho)^{T}+\sum_{i=1}^{s} \pm v_{i} \frac{\partial P}{\partial \rho} & * & * \\
+\mathcal{B}_{v}(\rho) Y(\rho)+Y(\rho)^{T} \mathcal{B}_{v}(\rho)^{T} & & \\
\mathcal{B}_{d}(\rho)^{T} & -\gamma I & * \\
\mathcal{C}_{z}(\rho) P(\rho)+\mathcal{D}_{z v}(\rho) Y(\rho) & \mathcal{D}_{z d}(\rho) & -\gamma I
\end{array}\right)<0
$$

then, there exists an LPV parameter-dependent statefeedback controller which guarantees closed loop stability and an upper bound $\gamma>0$ of the $\mathcal{L}_{2}$-gain of the closed loop system from $d$ to $z$ for any $\rho \in X_{\rho}$.

Finally, the parameter dependent state feedback is given by: $F(\rho)=-Y(\rho) P(\rho)^{-1}$.

In this work, a grid based approach is proposed since the LPV model is not necessarily affine or rationally dependent on $\rho$. Note that a grid-based LPV model is a collection of state space systems on a gridded domain of parameter values, as illustrated in Fig. 8.

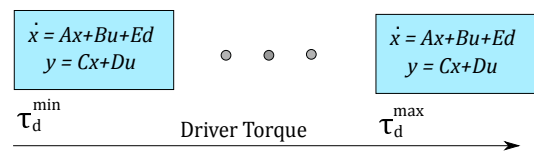

Figure 8: EPS LPV Models on a linear grid

In order to solve the LMI problem (14) for all point of the gridded domain, the matrices $P(\rho)$ and $Y(\rho)$ are expressed as a function of $\rho$ in order to compute an approximate solution over the infinite dimensional set. Here, a polynomial parameter dependency has been chosen which is close to an usual shape of the steering 
characteristic curve; for more details on how to choose the parameter dependency of the Lyapunov matrix see, Abbas et al. (2014); Wu et al. (1996).

$$
\begin{aligned}
& P(\rho)=P_{0}+\rho P_{1}+\rho^{2} P_{2} \\
& Y(\rho)=Y_{0}+\rho Y_{1}+\rho^{2} Y_{2}
\end{aligned}
$$

where $P_{0}, P_{1}, P_{2}, Y_{0}, Y_{1}$ and $Y_{2}$ are constant matrices and can be found solving (14).

The state feedback gain $F(\rho)$ is obtained here by solving the LMIs (14) for the whole gridded domain, using YALMIP interface Lfberg (2004) and SeDuMi solver Sturm (1999). An alternative solution would be to use the toolbox LPVTOOLS Hjartarson et al. (2015).

\subsection{Frequency domain analysis}

Theorem 1 has been solved using the following grid $\rho=\left[\begin{array}{lllllll}-10 & -5 & -1 & 0 & 1 & 5 & 10\end{array}\right] \mathrm{Nm}$ and considering the LPV system designed subject to an assistance curve $K(\rho)=\left[\begin{array}{lllllll}1.5 & 2 & 1 & 0 & 1 & 2 & 1.5\end{array}\right]$. In this case, the grid domain of $\rho$ has been defined up to $\pm 10 \mathrm{Nm}$ which represents the common measuring range of a torque sensor Bosch (2017). Moreover, $\pm 1 \mathrm{Nm}$ and $\pm 5 \mathrm{Nm}$ seem adequate breaking points regarding a characteristic curve Zhang et al. (2009) as not much assist power is required at low steering torque contrary to high steering torque where more assist power is expected.

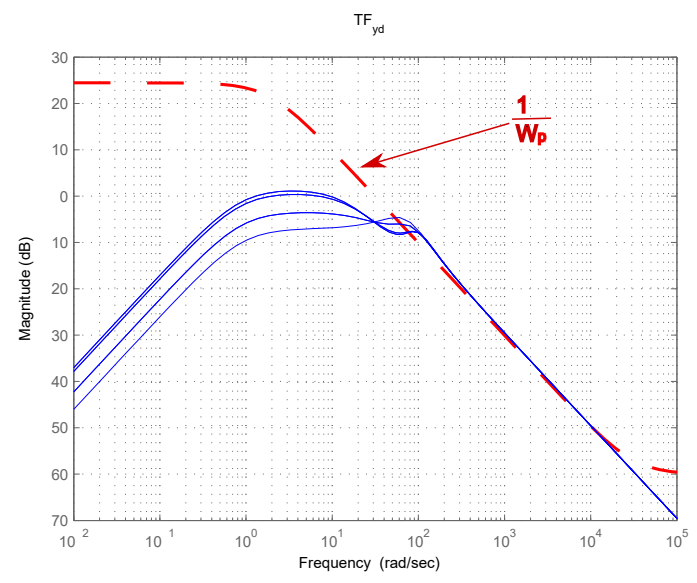

Figure 9: Frequency response regarding performance

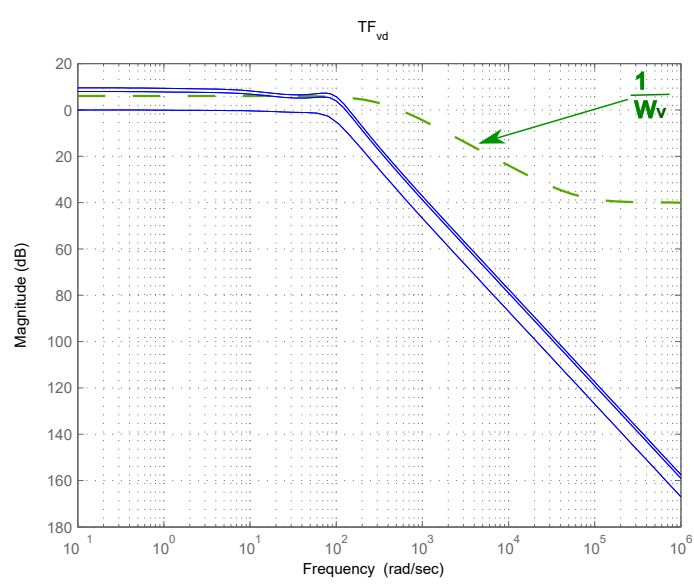

Figure 10: Frequency response regarding actuator constraint

In Fig. 9 and Fig. 10 the closed-loop performances for all frozen parameters of the grid, are compared with the specified design objectives. Fig. 9 illustrates the transfer $\frac{\dot{\theta}_{c}}{d}$ and $W_{p}^{-1}$. Similarly, Fig. 10 shows the frequency responses of $\frac{v}{d}$ and $W_{v}^{-1}$. In both cases, the requirements are well achieved ensuring the $H_{\infty}$ performance. Moreover, compared to the Bode plots in Fig. 4 (the free of state feedback control case), Fig. 9/Fig. 10 show a low frequency attenuation around $10 \mathrm{~Hz}$. Hence, a better steer feeling is obtained as less disturbance is pulled up to the hand-wheel, so to the driver.

\section{Observer design for Practical implementation}

First this section details the observer proposed for practical implementation of the LPV state feedback control for the real EPS system. Indeed a driver torque estimation method is needed, since a torque sensorless EPS system is considered (the complete observer-based control scheme is shown in Fig. 13).

The whole strategy is compared in simulation with the current industrial solution (it is worth noting that the industrial solution uses the torque sensor measurement).

\subsection{Observer design}

This section briefly recalls some results presented in Yamamoto et al. (2015) where an $\mathcal{H}_{\infty} / \mathcal{H}_{2}$ PI observer has been proposed, for more details on such observer design methods refer to Koenig (2005).

Let us recall the EPS system state representation (8):

$$
\begin{cases}\dot{x} & =A x+B u+E d+W w \\ y & =C x+N n\end{cases}
$$

where the measured outputs are the steering wheel and assist motor angle, usual on-board sensors in vehicles. 
The road reaction force acts in low frequencies, it is a disturbance to be rejected on the driver torque estimation process. To this aim, let us first introduce $W_{w}(s)=\frac{w}{\bar{w}}$ a weighting function to specify the frequency range of interest on which the disturbance $w$ should be attenuated. The state space representation is expressed as:

$$
W_{w}(\cdot) \begin{cases}\dot{x}_{w} & =A_{w} x_{w}+B_{w} \bar{w} \\ w & =C_{w} x_{w}+D_{w} \bar{w}\end{cases}
$$

The design scheme is then given as in Fig. 11.

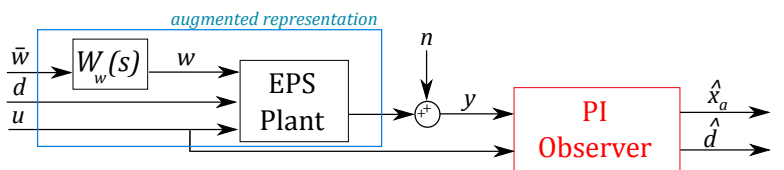

Figure 11: Proposed PI observer design

The Proportional Integral (PI) observer is synthesized considering the assumption that the driver torque is slowly time varying $\dot{d}=0$, as in the form:

$$
\left\{\begin{array}{l}
\dot{\hat{x}}_{a}=A_{a} \hat{x}_{a}+E_{a} \hat{d}+L_{p}\left(y-C_{a} \hat{x}_{a}\right)+B_{a} u \\
\dot{\hat{d}}=L_{i}\left(y-C_{a} \hat{x}_{a}\right)
\end{array}\right.
$$

where the notation $-a$ concerns the augmented representation and $x_{a}=\left(x^{T} x_{w}^{T}\right)^{T}$

Hence, the state-space representation of the estimation error is given by:

$$
\left\{\begin{array}{l}
\dot{e_{x}}=\left(A_{a}-L_{p} C_{a}\right) e_{x}+E_{a} e_{d}+W_{a} \bar{w}+L_{p} N n \\
\dot{e_{d}}=-L_{i} C_{a} e_{x}-L_{i} N n
\end{array}\right.
$$

where $e_{x}=\left(x_{a}-\hat{x}_{a}\right), e_{d}=(d-\hat{d})$.

The considered observer design problem is a mixed $\mathcal{H}_{\infty} / \mathcal{H}_{2}$ problem subject to pole placement. It consists in finding the observer gain $L_{a}=\left(\begin{array}{ll}L_{p}^{T} & L_{i}^{T}\end{array}\right)^{T}$ where the observer poles are chosen in a region of the left-half plane (see Chilali and Gahinet (1996)), while minimizing the $\mathcal{H}_{\infty}$ and $\mathcal{H}_{2}$ (generalized form in Scherer and Weiland (2000)) performance objectives as:

1. $\left\|T_{e_{d} \bar{w}}\right\|_{\infty}<\gamma_{\infty}$ minimizes the effect of road disturbances on the driver torque estimation error

2. $\left\|T_{e_{d} n}\right\|_{2}<\gamma_{2}$ minimizes the effect of measurements noise on the driver torque estimation error.

Theorem 2. The mixed $\mathrm{H}_{\infty} / \mathrm{H}_{2}$ observation problem is solved if there exist $P=P^{T}>0$ and a matrix $Y$ such that the following LMIs are satisfied:

$$
\begin{array}{ccc}
A_{a d}^{T} P+P A_{a d}-C_{a d}^{T} Y^{T}-Y C_{a d}+2 \lambda_{\min } P & <0 \\
\left(\begin{array}{cc}
A_{a d}^{T} P+P A_{a d}-C_{a d}^{T} Y^{T}-Y C_{a d}+D_{a d}^{T} D_{a d} & P W_{a d} \\
* & -\gamma_{\infty}^{2}
\end{array}\right) & <0 \\
\left(\begin{array}{cc}
A_{a d}^{T} P+P A_{a d}-C_{a d}^{T} Y^{T}-Y C_{a d} & -Y N \\
* & -I
\end{array}\right) & <0 \\
\left(\begin{array}{cc}
P & D_{a d}^{T} \\
* & \gamma_{2}^{2}
\end{array}\right) & & >0
\end{array}
$$

where $Y=P L_{a}$. The observer gain $L_{a}$ is deduced as $L_{a}=P^{-1} Y$.

However, it is not possible to minimize simultaneously both $\mathrm{H}_{\infty}$ and $\mathrm{H}_{2}$ criteria. Therefore, a linear combination of $\gamma_{\infty}$ and $\gamma_{2}$ is considered to solve the problem as follows:

$$
\min \alpha \gamma_{\infty}+(1-\alpha) \gamma_{2}
$$

where $\alpha \in[0 ; 1], \gamma_{\infty}$ and $\gamma_{2}$ are positive scalars.

The observer described in (19) with gain $L_{a}=P^{-1} Y$, is an $\mathrm{H}_{\infty} / \mathrm{H}_{2} \mathrm{PIO}$ with pole placement.

In Fig. 12, a Pareto-like optimal (trade-off) curve between $H_{\infty}$ and $H_{2}$ performance levels $\left(\gamma_{\infty}\right.$ and $\left.\gamma_{2}\right)$ illustrates the multi-objective optimization trade-off . Indeed, Pareto optimality corresponds to the fact that $\gamma_{\infty}$ ( $H_{\infty}$ performance level) can not be reduced without increasing $\gamma_{2}\left(H_{2}\right.$ performance level).

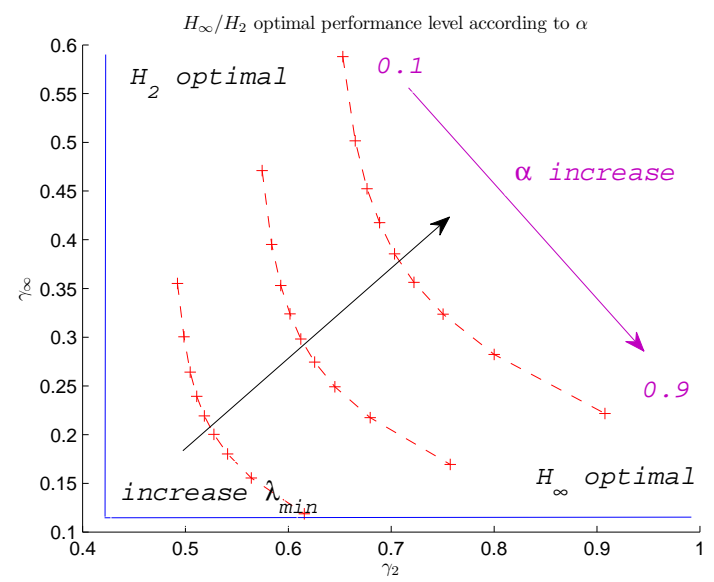

Figure 12: $H_{\infty} / H_{2}$ performance evaluation according to $\alpha$

Fig. 12 displays $\gamma_{\infty}$ on the $\mathrm{x}$-axis and $\gamma_{2}$ on the $\mathrm{y}$ axis obtained by resolving the $\mathrm{H}_{\infty} / \mathrm{H}_{2}$ optimal problem subject to various value on $\alpha$ computed on the range $[0.1: 0.9]$ with a step of 0.1 . Considering $\alpha$ close to 1 almost corresponds to solve the LMIs under $\gamma_{o p t}=\gamma_{\infty}$; in such a case $\gamma_{\infty}$ decreases while $\gamma_{2}$ increases. Reciprocally, $\alpha$ close to 0 almost corresponds to solving the 


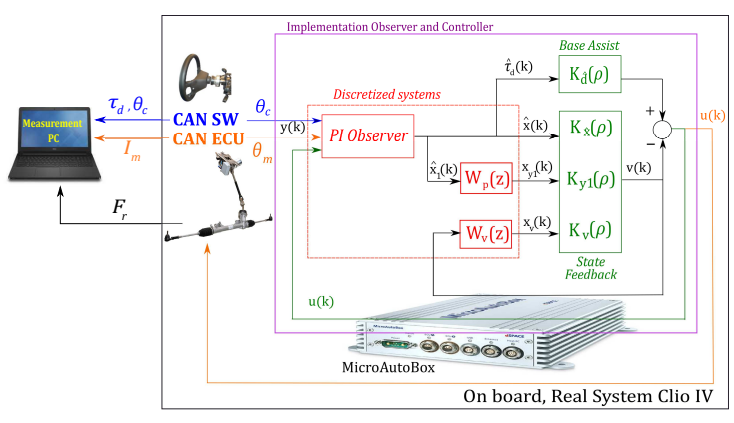

Figure 13: Strategy PIO+LPV implementation on real system

LMIs under $\gamma_{o p t}=\gamma_{2}$; in this case $\gamma_{2}$ decreases while $\gamma_{\infty}$ increases.

Furthermore, it is important to notice that the choice of the LMI regions for pole placement may affect the global $\mathrm{H}_{\infty} / \mathrm{H}_{2}$ performance since a fast response requirement generates an harder constraint. To illustrate this issue, three curves are presented according to three different values of $\lambda_{\min }(-40,-50,-60)$ where a larger real part choice involves to increase $\gamma_{\infty}$ and $\gamma_{2}$.

\subsection{Global implementation scheme}

As illustrated through the interfaces, the proposed PI observer method requires only the following measurements: the steering wheel angle $\theta_{c}$ and the motor angle $\theta_{m}$ which are available signals on newly mass-produced vehicles.

Furthermore, the additional transfers $W_{v}(z)$ and $W_{p}(z)$ shown in Fig. 13 and introduced in the design of the controller in section 3 , are implemented to obtain the full states involved in the LPV extended state feedback.

Remark 3. It is important to note that the whole closedloop stability (including the PI observer and LPV statefeedback controller) has been verified according to the robust stability characterization, considering a parameter varying Lyapunov function (see Wu (1995)). More detailed analysis of the effect of uncertain scheduling parameters may be studied following Daafouz et al. (2008).

According to implementation issue, such an observer is simple to implement compared to a sliding mode as in Marouf et al. (2010).

\subsection{Some remarks and comparison with the industrial solution that uses a torque sensor}

First, let us emphasize that the experimental tests (presented later in section 7) have obtained a prototype C-EPS system for which the conditions required for the implementation of the industrial solution are not met since it needs the torque sensor signal.
However, it seems still interesting to highlight the overall vehicle handling (steering and feeling) achieved with the proposed method. The aim is to ensure that the sensorless LPV solution provides as good results as the industrial solution with the additional advantage that it is not using the torque sensor signal (cost reduction). To this end, the PI observer and LPV state-feedback controller (as represented in Fig. 5) have been compared to an industrial control law (structure based on a PI controller that uses the torque sensor signal).

Considering the performance objectives, let us remind that there are no specific quantification regarding EPS system performances El-Shaer (2008). The analysis is characterized in a subjective way according to the driver's profile i.e. his steering feel and comfort. Nevertheless, some guidelines allow to evaluate the steering feel issues looking at the evolution of the driver torque $\tau_{d}$ function of the steering wheel angle $\theta_{c}$, as explained in Morita et al. (2009), where, for illustration, the steering ability is expressed as the smoothness of the curve seen in Fig. 14.

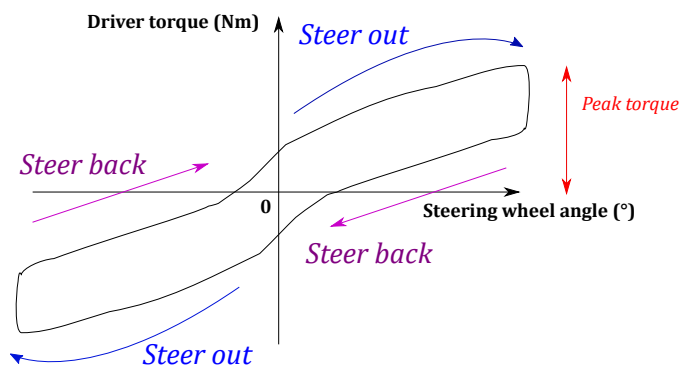

Steering smooth

Figure 14: EPS Characteristics - Steering feeling

The comparison in between the industrial and the LPV solutions is shown in Fig. 15. A sinusoidal driver input at $5 \mathrm{Nm}$, with frequency $0.05 \mathrm{~Hz}$, and vehicle speed $15 \mathrm{~km} / \mathrm{h}$ has been performed. Note that, in this simulation case, the driver turns the steering wheel almost entirely (from around -360 to +360 ) with a torque level of $5 \mathrm{Nm}$ that can be considered as a common assistance level. The result of the proposed method may then be considered as convenient since it represents a typical functional range. Moreover, the on-centre steering characteristic is similar for both strategies, even if the steer back and steer out are slightly different. This performance assessment emphasizes that the LPV approach is efficient. 


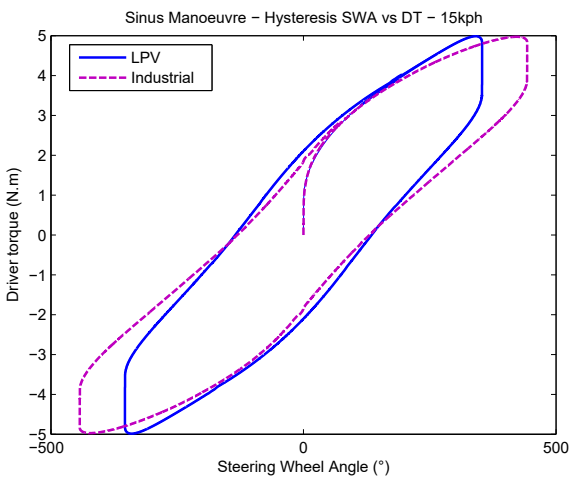

Figure 15: Controller performance comparisons at $15 \mathrm{kph}$

Hence, the LPV extended state-feedback controller based on a PI observer allows to ensure driving performances close to an existing industrial solution, developed using an empirical approach. Moreover, it uses only common on-board sensors (no torque sensor) and then reduces the cost compared to the industrial solution. Besides, the closed loop performances are achieved through the choice of the weighting functions, that can handle as well the robustness to model uncertainties. Of course a final tuning (in particular of the parameters of the weighting functions) may sometimes be needed in order to get optimal experimental results.

The next section presents the experimental results obtained with the implemented LPV strategy on a test car.

\section{Experimental results}

In this part, the experimental facility is presented as well as some test cases realized at two different vehicle speeds: low $(15 \mathrm{~km} / \mathrm{h})$ and average $(30 \mathrm{~km} / \mathrm{h})$.

\subsection{Experimental facility}

The test track on which the experiments are carried out is shown in Fig. 16. The various patterns drawn on the ground allow to evaluate the EPS system handling performances at different vehicle speeds.

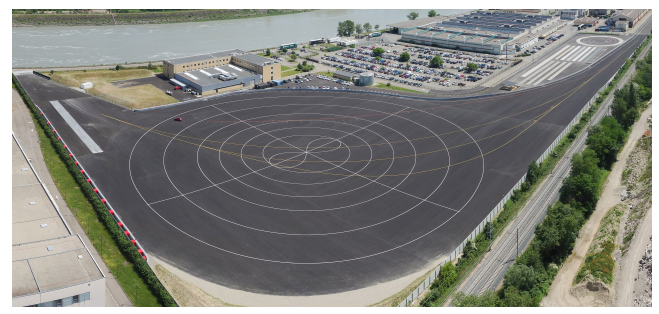

Figure 16: Test track

\subsection{Vehicle tests at $15 \mathrm{~km} / \mathrm{h}$}

For the driver, this test consists in turning the steering wheel over the entire operating range at $15 \mathrm{~km} / \mathrm{h}$ (in order to travel on the full rack stroke). Therefore, the test is referred to as a lock-to-lock manoeuvre, performed at slow dynamics. Indeed, the variations of the steering wheel angular position and speed during the test are shown in Fig. 17. The steering wheel speed is less than $100^{\circ} / \mathrm{s}$ and the maximum angle is around $\pm 630^{\circ}$ (this wide range is characteristic of the considered C-EPS prototype).
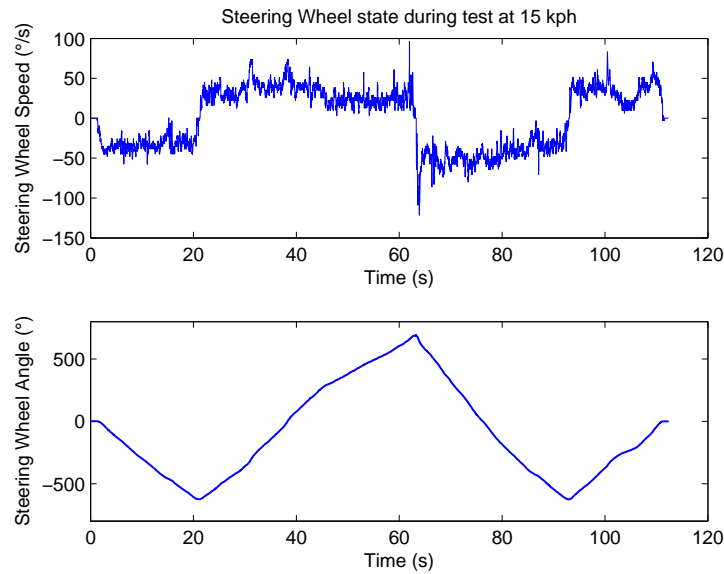

Figure 17: Steering wheel speed and angle evolution at $15 \mathrm{~km} / \mathrm{h}$

Fig. 18 shows the comparison between the measured (green) and estimated (red) driver torque. A quantitative error analysis is performed using both following criteria:

- Root Mean Square Error (RMSE)

$$
R M S E=\sqrt{\frac{\sum_{i=1}^{n}(d-\hat{d})}{n}}
$$

where $d$ is the measured driver torque and $\hat{d}$ is the estimated driver torque obtained from the PI observer.

- Normalized Root Mean Square Error (NRMSE) over the range of the measured data $\left[d_{\min } ; d_{\max }\right]$.

$$
N R M S E=\frac{R M S E}{d_{\max }-d_{\min }}
$$

Here, the following values are obtained:

$\mathrm{RMSE}=1.15 \mathrm{Nm}$ and $\mathrm{NRMSE}=4.84 \%$.

The implemented observer then provides a good estimation of the driver torque. 


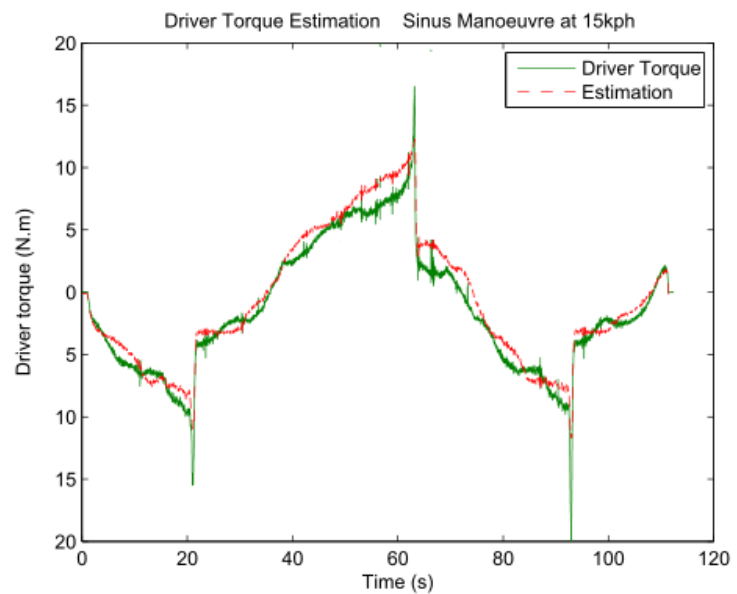

Figure 18: Driver torque estimation at $15 \mathrm{~km} / \mathrm{h}$

Fig. 19 shows the evolution of the EPS torque inputs. The assistance torque (purple) provides some additional torque to the driver (green) in order to reduce the required effort to overcome the road reaction torque (blue). Note that the amount without assistance would be large (around $\sim 12 \mathrm{Nm}$ ) whereas, thanks to the proposed strategy, the average steering torque is close to $6 \mathrm{Nm}$. The assist motor reduces almost by half the effort required by the driver. It could also be noticed that the assist torque increases for large steering wheel ranges.

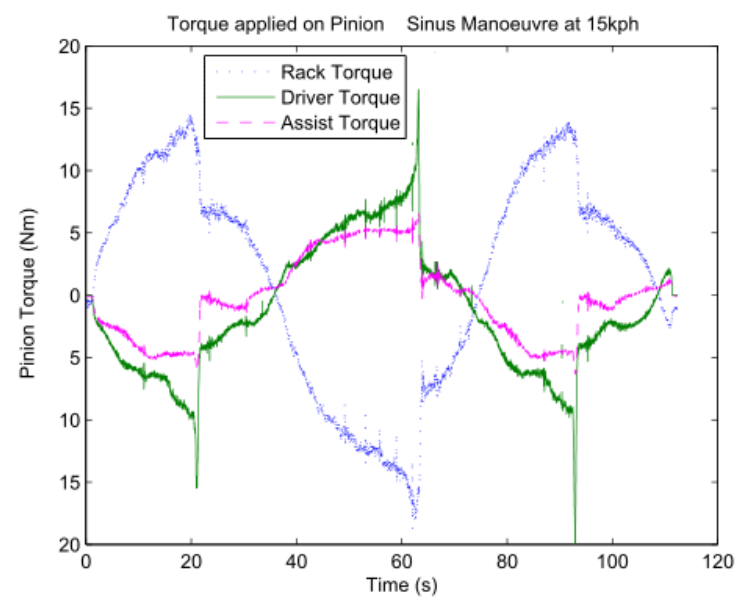

Figure 19: Evolution of involved torques $15 \mathrm{~km} / \mathrm{h}$

\subsection{Vehicle tests at $30 \mathrm{~km} / \mathrm{h}$}

In this case, the driver performs a sinus manoeuvre at $30 \mathrm{~km} / \mathrm{h}$, with a steering action on a nominal angular range (without loss of grip) in low frequency. The variations of the steering wheel angular position and speed during this test are shown in Fig. 20. The steering wheel speed remains lower than $100^{\circ} / \mathrm{s}$ and the driver makes almost one turn of the handwheel at each side, $\pm 360^{\circ}$.
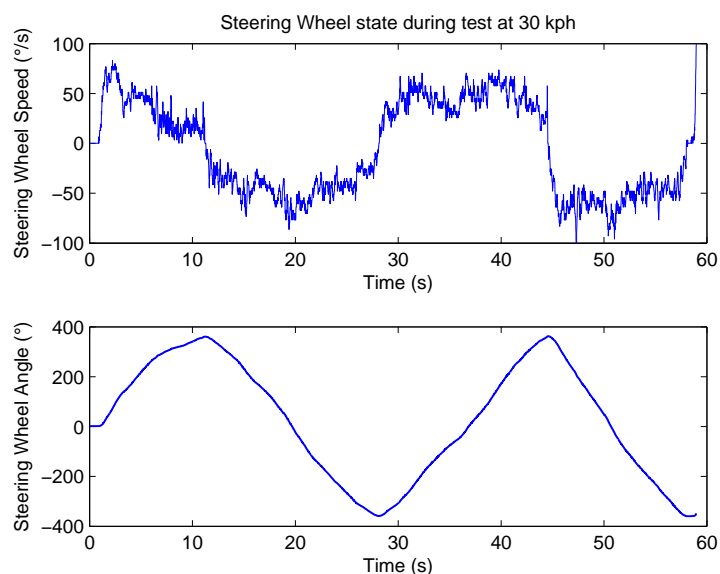

Figure 20: Steering wheel speed and angle evolution at $30 \mathrm{~km} / \mathrm{h}$

In Fig. 21, a comparison between the measured (green) and estimated (red) driver torque is shown. The quantitative error analysis gives:

RMSE $=1.27 \mathrm{Nm}$ and $\mathrm{a}$ NRSE $=5.75 \%$,

which means that a good estimation is obtained even at a nominal vehicle speed of $30 \mathrm{~km} / \mathrm{h}$.

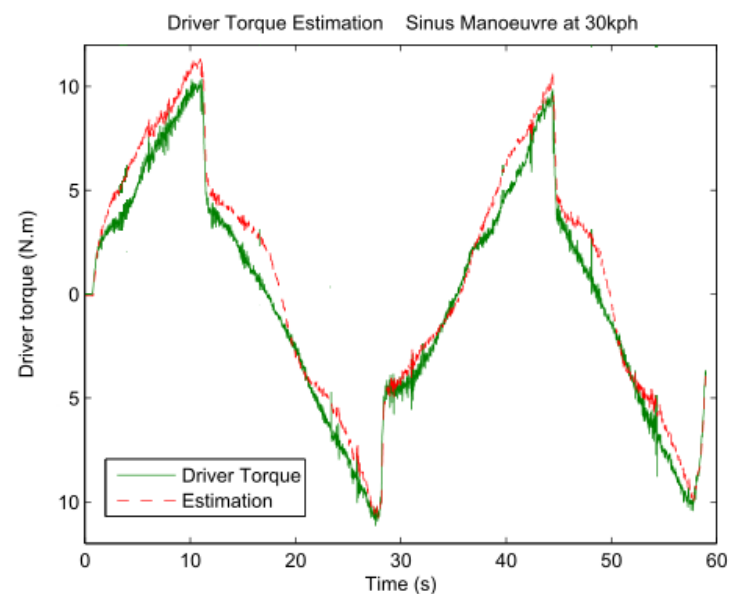

Figure 21: Driver torque estimation at $30 \mathrm{~km} / \mathrm{h}$

Fig. 22 shows that the driver torque (green) and the assistance torque (purple) act in the same direction (the torque distribution is almost fifty-fifty) to counteract the road reaction torque (blue). However, when an higher road torque $(\sim 17 \mathrm{Nm})$ is applied at $30 \mathrm{~km} / \mathrm{h}$, the driver's effort reduction at large steering wheel turn is less important. This could be improved by considering the vehicle speed in the control design step. 


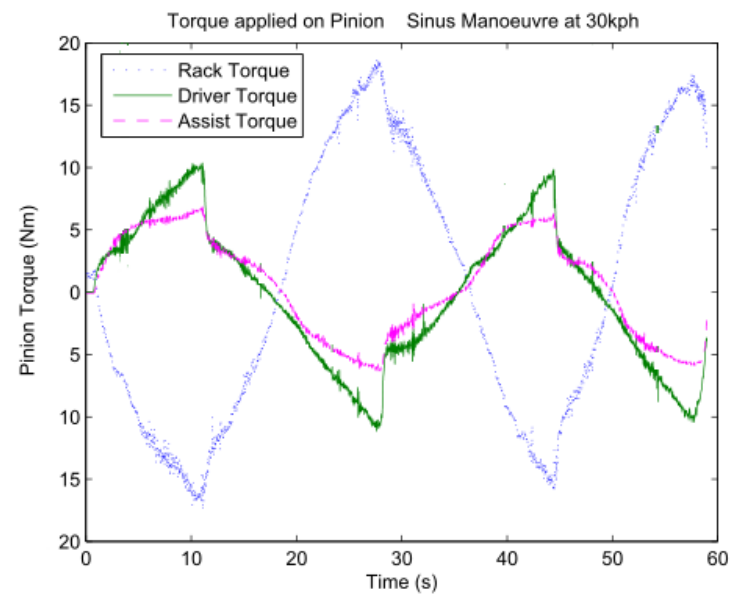

Figure 22: Evolution of involved torques $30 \mathrm{~km} / \mathrm{h}$

Finally, in Fig. 23, the hysteresis curve of the driver torque w.r.t the steering wheel angle allows to evaluate the EPS performance, as suggested in Yamamoto and Nishimura (2011). Let us notice that, for the test at $15 \mathrm{~km} / \mathrm{h}$, the driver torque in the steering wheel centre (i.e. for steering angles $<90^{\circ}$ ) is less than $5 \mathrm{Nm}$, then it increases for large steering wheel angle ranges, but, still, it remains at an acceptable level $<10 \mathrm{Nm}$. Moreover, the driver torque for the test at $30 \mathrm{~km} / \mathrm{h}$ is higher than the one at $15 \mathrm{~km} / \mathrm{h}$, which meets the EPS system requirements regarding feeling consistency.

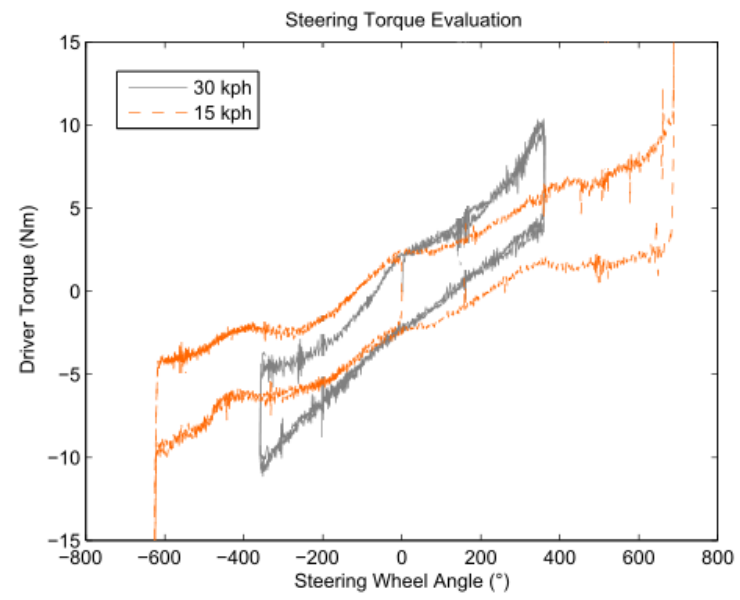

Figure 23: Hysteresis $\theta_{c}$ VS $\tau_{d}$ at $15 \mathrm{~km} / \mathrm{h}$ and $30 \mathrm{~km} / \mathrm{h}$

\section{Conclusion}

This paper has presented the design and implementation of an LPV state-feedback controller based on a PI observer, for a C-EPS system, without using any torque sensor. The observer has been designed subject to pole placement and $\mathcal{H}_{\infty} / \mathcal{H}_{2}$ minimization objectives. For control purpose, the EPS system model is written as an LPV system, function of the driver torque, and an LPV state-feedback controller has been designed using the gridding approach. Although the sequential design does not guarantee the closed-loop stability of the non-linear system, robust stability has been verified a posteriori, which has been confirmed experimentally. According to the experimental results, the proposed method performs an accurate estimation of the driver torque while providing a suitable amount of assistance to the driver.

Finally, this approach tends to meet cost competitiveness through reducing EPS production costs, by removing the torque sensor and by providing a model-based control strategy that ensures stability and performances and that can be easily reproduced by control engineers. This study is then a proof-of-concept of the industrial interest of torque sensorless controlled C-EPS systems.

Future works may concern the improvements of the observer performances considering some uncertainties for the mechanical parameters (for instance, damping or viscous friction values). Furthermore, the LPV control may be extended considering additional varying parameters as the vehicle speed.

\section{Acknowledgements}

This work has been supported by JTEKT corporation in Japan, Hanazono plant.

\section{Appendix A. Matrices C-EPS system model}

The state-space matrices for the C-EPS system (8) are defined as follows:

$$
A=\left(\begin{array}{cccc}
-\frac{D_{c}+B_{c}}{J_{c}} & \frac{D_{c}}{R_{m} J_{c}} & -\frac{K_{c}}{J_{c}} & \frac{K_{c}}{R_{m} J_{c}} \\
1 & 0 & 0 & 0 \\
\frac{D_{c}}{R_{m} J_{e q}} & a_{32} & \frac{K_{c}}{R_{m} J_{e q}} & a_{34} \\
0 & 0 & 1 & 0
\end{array}\right)
$$

where $a_{32}=-\frac{1}{J_{e q}}\left(\frac{D_{c}}{R_{m}^{2}}+D_{r} \frac{R_{p}^{2}}{R_{m}^{2}}+B_{m}\right)$ and $a_{34}=$ $-\frac{1}{J_{e q}}\left(\frac{K_{c}}{R_{m}^{2}}+K_{r} \frac{R_{p}^{2}}{R_{m}^{2}}\right)$.

$$
B=\left(\begin{array}{c}
0 \\
0 \\
\frac{1}{J_{e q}} \\
0
\end{array}\right), E=\left(\begin{array}{c}
\frac{1}{J_{c}} \\
0 \\
0 \\
0
\end{array}\right), W=\left(\begin{array}{c}
0 \\
0 \\
\frac{1}{R_{m} J_{e q}} \\
0
\end{array}\right) \text { and the output }
$$

matrix $C=\left(\begin{array}{llll}0 & 1 & 0 & 0 \\ 0 & 0 & 0 & 1\end{array}\right)$. 


\section{Appendix B. Matrices C-EPS LPV system model}

\section{Appendix B.1. Express C-EPS LPV system}

The state-space matrix $A(\rho)$ in (9) is further expressed below, recalled that $K(\rho)$ is a scalar.

$A(\rho)=\left(\begin{array}{cccc}-\frac{D_{c}+B_{c}}{J_{c}} & -\frac{K_{c}}{J_{c}} & \frac{D_{c}}{R_{m} J_{c}} & \frac{K_{c}}{R_{m} J_{c}} \\ 1 & 0 & 0 & 0 \\ \frac{D_{c}}{J_{e q}}\left(\frac{1}{R_{m}}+K(\rho)\right) & \frac{K_{c}}{J_{e q}}\left(\frac{1}{R_{m}}+K(\rho)\right) & a r_{33} & a r_{34} \\ 0 & 0 & 1 & 0\end{array}\right)$

where $a r_{33}=-\frac{D_{c}}{J_{e q} R_{m}}\left(\frac{1}{R_{m}}+K(\rho)\right)-\frac{1}{J_{e q}}\left(D_{r} \frac{R_{p}^{2}}{R_{m}^{2}}+B_{m}\right)$ and $a_{34}=-\frac{K_{c}}{J_{e q} R_{m}}\left(\frac{1}{R_{m}}+K(\rho)\right)-\frac{K_{r}}{J_{e q}} \frac{R_{p}^{2}}{R_{m}^{2}}$.

\section{Appendix B.2. Generalized LPV EPS system}

The matching between both expressions (12) and (13) is: $\mathcal{A}_{\Sigma}(\rho)=\left(\begin{array}{ccc}A(\rho) & 0 & 0 \\ 0 & A_{v} & 0 \\ B_{p} C_{\dot{\theta}_{c}} & 0 & A_{p}\end{array}\right), \mathcal{B}_{v}(\rho)=\left(\begin{array}{c}B \\ B_{v} \\ 0\end{array}\right)$, $\mathcal{B}_{d}(\rho)=\left(\begin{array}{l}E \\ 0 \\ 0\end{array}\right), C_{z}(\rho)=\left(\begin{array}{ccc}0 & C_{v} & 0 \\ D_{p} C_{\dot{\theta}_{c}} & 0 & C_{p}\end{array}\right), \mathcal{D}_{z v}(\rho)=$ $\left(\begin{array}{c}D_{v} \\ 0\end{array}\right), \mathcal{D}_{z d}(\rho)=0$

\section{Appendix C. List of notations}

In the table below Tab. C.3, some recursive notations have been summed up.

\begin{tabular}{ll} 
Notation & Description \\
\hline$\tau_{d}$ & driver torque \\
$\theta_{c}$ & steering wheel angle \\
$\tau_{m}$ & assist motor torque \\
$\theta_{m}$ & assist motor angle \\
$W_{x}(\cdot)$ & Weighting functions \\
EPS & Electric Power Steering \\
LMI & Linear Matrix Inequality \\
LPV & Linear Parameter Varying \\
LTI & Linear Time Invariant \\
PIO & Proportional Integral Observer \\
\hline
\end{tabular}

Table C.3: List of useful notations

Abbas, H., Ali, A., Hashemi, M., Werner, H., 2014. Lpv statefeedback control of a control moment gyroscope. Control Engineering Practice, 129 - 137.

Badawy, A., Zuraski, J., Bolourchi, F., Chandy, A., 1999. Modeling and analysis of an electric power steering system. SAE Technical Paper, 1999-01-0399.
Bosch, 2017. Servoelectric electric power steering system - Torque sensor. technical datasheet.

Chabaan, R., Wang, L., 2001. Control of electrical power assist systems: $\mathcal{H}_{\infty}$ design, torque estimation and structural stability. JSAE Review, 435 - 444.

Chilali, M., Gahinet, P., 1996. $h_{\infty}$ design with pole placement constraints: an lmi approach. IEEE Transactions on Automatic Control 41, 358-366.

Cholakkal, S., Chen, X., 2009. Fault tolerant control of electric power steering using robust filter-simulation study. IEEE Vehicle Power and Propulsion Conference, 1244 - 1249.

Coudon, J., 2007. Algorithmes de commande pour le pilotage d'une direction découplée. Ph.D. thesis, Institut National Polytechnique de Grenoble.

Daafouz, J., Bernussou, J., Geromel, J. C., Aug 2008. On inexact lpv control design of continuous time polytopic systems. IEEE Transactions on Automatic Control 53 (7), 1674-1678.

El-Shaer, A., 2008. Robust control design of electric power steering systems. Ph.D. thesis, University of California, Berkeley.

El-Shaer, A., Sugita, S., Tomizuka, M., 2009. Robust fixed-structure controller design of electric power steering systems. American Control Conference, 445-450Saint-Louis, USA.

Hjartarson, A., Seiler, P., Packard, A., 2015. Lpvtools: A toolbox for modeling, analysis, and synthesis of parameter varying control systems. IFAC-PapersOnLine 48, 139 - 145

Illán, J. T., Ciarla, V., De Wit, C. C., 2011. Oscillation annealing and driver/tire load torque estimation in Electric Power Steering systems. Proceedings of the IEEE International Conference on Control Applications, 1100-1105.

Kim, J. H., Song, J. B., 2002. Control logic for an electric power steering system using assist motor. Mechatronics 12, 447-459.

Koenig, D., 2005. Unknown input proportional multiple-integral observer design for linear descriptor systems: Application to state and fault estimation. IEEE Transactions on Automatic Control 50, $212-217$.

Kozaki, Y., Hirose, G., Sekiya, S., Miyaura, Y., 1999. Electric power steering (eps). NSK Technical Journal Motion and Control 6, 9 15.

Lawson, M., Chen, X., 2008. Controller design for electric power steering system using t-s fuzzy model approach. IEEE International Conference on Control Applications, 486-491Texas, USA.

Lfberg, J., 2004. Yalmip: A toolbox for modeling and optimization in matlab. IEEE International Symposium on Computer aided control systems design.

Marouf, A., Djemaï, M., Sentouh, C., Pudlo, P., 2010. Driver torque and road reaction force estimation of an electric power assisted steering using sliding mode observer with unknown inputs. IEEE Conference on Intelligent Transportation Systems, Proceedings, ITSC, 354-359Madeira Island, Portugal.

Marouf, A., Djemaï, M., Sentouh, C., Pudlo, P., 2012. A new control strategy of an electric-power-assisted steering system. IEEE Transactions on Vehicular Technology 61 (8), 3574-3589.

Marouf, A., Sentouh, C., Djemaï, M., Pudlo, P., 2011. Control of an electric power assisted steering system using reference model. IEEE Conference on Decision and Control and European Control Conference, 6684-6690Orlando, USA.

Matsuoka, H., 2016. Development and future outlook of steering systems. JTEKT Engineering Journal, $8-13$.

Mehrabi, N., Azad, N. L., McPhee, J., 2011. Optimal disturbance rejection control design for electric power steering systems. IEEE Conference on Decision and Control and European Control Conference, 6584-65890rlando, USA.

Morita, Y., Yokoi, A., Iwasaki, M., Ukai, H., Matsui, N., Ito, N., Uryu, N., Mukai, Y., 2009. Controller design method for electric power steering system with variable gear transmission system using de- 
coupling control. IEEE Industrial Electronics Conference.

Noguchi, M., 2001. Trends and future prospects regarding steering system technology. Koyo Engineering Journal, 37 - 41.

Parmar, M., Hung, J., 2004. A sensorless optimal control system for an automotive electric power assist steering system. IEEE Transactions on Industrial Electronics, 290 - 298.

Qun, Z., Juhua, H., 2009. The development of control unit in automotive electric power steering system. Asia-Pacific Conference on Information Processing.

Rongyun, Z., Linfeng, Z., Wuwei, C., He, H., 2015. Research on eps system based on $1 \mathrm{pv} / h_{\infty}$ control and its hardware in loop test. China Mechanical Engineering 26, 545 - 552.

Saifia, D., Chadli, M., Karimi, H., Labiod, S., 2014. Fuzzy control for electric power steering system with assist motor current input constraints. Journal of the Franklin Institute, 562 -576.

Scherer, C., Weiland, S., 2000. Linear matrix inequalities in control. Delft University of Technology.

Sename, O., Gaspar, P., Bokor, J., 2013. Robust control and linear parameter varying approaches: Application to vehicle dynamics. Springer-Verlag.

Sturm, J., 1999. Using sedumi 1.02, a matlab toolbox for optimization over symmetric cones. Optimization Methods and Software, 625 653.

Wu, F., 1995. Control of linear parameter varying systems. Ph.D. thesis, University of California, Berkeley.

Wu, F., Yang, X., Packard, A., Becker, G., 1996. Induced $l_{2}$-norm control for $1 p v$ systems with bounded parameter variation rates. International Journal of Robust Nonlinear Control, 983 - 998.

Yamamoto, K., Koenig, D., Sename, O., Moulaire, P., 2015. Driver torque estimation in electric power steering system using an $h_{\infty} / h_{2}$ proportional integral observer. IEEE Conference on Decision and Control, 843 - 848Osaka, Japan.

Yamamoto, K., Nishimura, H., 2011. Control system design of electric power steering for a full vehicle model with active stabilizer. Journal of System Design and Dynamics 5, $789-804$.

Yang, T., 2015. A new control framework of electric power steering system based on admittance control. IEEE Transactions on Control Systems Technology, $762-769$.

Zhang, H., Zhang, Y., Liu, J., Ren, J., Gao, Y., 2009. Modeling and characteristic curves of electric power steering system. International Conference on Power Electronics and Drive Systems, 13901393. 